\title{
Determinación de la filiación en la procreación asistida*
}

\section{Enrique Varsi Rospigliosi**}

\section{RESUMEN}

El avance incontenible de la procreática avasalla el Derecho de familia, sobre todo en el tema filial, siendo la tendencia actual en la determinación del nexo filial la prevalencia de la voluntad, desplazando al aspecto biogenético, tendiendo a su desbiologización. La determinación de la filiación producto de la técnicas de reproducción asistida se focalizala en parentalidad voluntaria como un hecho juridico compuesto de elementos volitivos, sociales y afectivos, el vínculo genético quedó regalado para dar paso a la paternidad socioafectiva.

PALABRAS CLAVE: Filiación, ADN, socioafectividad, procreática

\section{ABSTRACT}

The unstoppable advance of the procreation overwhelms family law, especially in the filial issue. The prevalence of will is the current trend in the determination of the filial link, displacing the biogenetic aspect, tending to its debiologization. The determination of the affiliation, result of assisted reproduction techniques, is focus on volunteer parenthood as a legal event composed of volitional, social and affective elements; the genetic link is left to one side to give way to socio-affective paternity.

KEY WORDS: Affiliation, DNA, socio-affectivity, procreation.

* Artículo recibido el 15 de septiembre de 2016 y aceptado el 28 de noviembre de 2016.

** Doctor en Derecho. Profesor investigador de la Universidad de Lima. Investigador del Consejo Nacional de Ciencia, Tecnología e Innovación Tecnológica. Socio Internacional del Instituto Brasileño de Derecho de Familia. evarsi@correo.ulima.edu.pe 
SUMARIO

1. Introducción

2. Procreación y filiación

3. Determinación de la filiación

4. Principio biológico

5. Procreación asistida y filiación

6. Anonimato de la cesión y el derecho a conocer nuestro origen

7. Tipos de fecundación

8. Determinación de la paternidad

9. Determinación de la maternidad

10. Maternidad subrogada

11. Fecundación post mortem

12. Conclusión

\section{Introducción}

La procreación asistida representa una ventaja para aquellas parejas que adolecen de infertilidad. Les permite tener descendencia pero, a la vez, genera una serie de inconvenientes en materia legal: su calificación como derecho de la persona (derecho a la procreación y el derecho al hijo), su calidad de acto de libre disposición del cuerpo humano, la afectación del derecho a la intimidad, los intrincados problemas filiales que afectan el derecho a la identidad y la reducción y desplazamiento de la adopción.

Las técnicas de reproducción asistida pueden ser in o ex útero, de allí que se hable de inseminación y fecundación. Esta última suprime la unitas carnis (el coito), por ello se dice que es una concepción antinatural. Si se realizan con el material genético de los cónyuges -o convivientes- se denomina homóloga; si es con material de terceros (cedentes) o por maternidad subrogada, se denomina heteróloga.

A decir de Sesta, ${ }^{1}$ los problemas que presentan las técnicas de reproducción están en dos órdenes: el relativo a la licitud de la práctica de procreación asistida, y la modalidad de atribución del estatus del nacido a través de ellas. Es aquí donde la determinación de la filiación se presenta como un tema recurrente, considerando que las normas jurídicas fueron pensadas y estructuradas con base en la reproducción natural. Esto hace bastantes siglos, cuando ni siquiera

\footnotetext{
' SeSTA, Michele, "Filiazione", en Enciclopedia del Diritto, Aggiornamento, tomo 4, Milán, Giuffré, 2002, p. 594.
} 
era posible avizorar la inseminación artificial y, mucho menos, una gestación por sustitución.

El desarrollo y perfeccionamiento de la reproducción asistida ha determinado una revolución en el campo de la filiación "poniendo en crisis principios que hasta no hace mucho eran inamovibles". ${ }^{2}$ Con el boom de la procreación asistida, empiezan a surgir los problemas que antaño eran imprevisibles y que hoy son una realidad, ${ }^{3}$ proyectándose a situaciones inimaginables. Reproducción asistida y filiación son temas recurrentes y cotidianos. Van in crescendo, inconteniblemente, y en la mayoría de casos, no se puede frenar sus prácticas ni dar solución a los problemas derivados. Se requiere interés, para generar una solución eficiente y eficaz en beneficio del ser humano, la familia y la sociedad, así como hacer frente al avance de las técnicas de reproducción asistida. ${ }^{4}$

La filiación es el vínculo jurídico entre padres e hijos. Normalmente, tiene como presupuesto determinante el vínculo biológico (filiación por naturaleza), pero puede encontrar su fuente en la ley (filiación por adopción). ${ }^{5}$ Esta amplia noción de filiación se diferencia de los restantes institutos que conforman el derecho de familia, tomando en cuenta las permanentes alteraciones que experimenta. Tales alteraciones se presentan frente a dos variables principales: a) los cambios sociales, y b) el impacto biotecnológico. Mientras la adopción y la igualdad de los hijos nacidos dentro o fuera del matrimonio son consecuencia de variantes sociales, la incorporación de la prueba genética del ADN y las técnicas de reproducción humana asistida son resultado de la incidencia de la biotecnología en el ámbito jurídico. ${ }^{6}$

Hay dos formas de filiación tradicionales: por naturaleza, derivada de la procreación, y por adopción, donde el vínculo nace sin depender del hecho biológico. A éstas debemos sumar la filiación, producto de las técnicas de repro-

\footnotetext{
${ }^{2}$ Kemelmajer de Carlucci, Aida; Herrera, Marisa y lloveras, Nora, Tratado de Derecho de Familia (Según el Código Civil y Comercial de 2014), tomo 2, Santa Fe, Rubinzal-Culzoni, 2014, p. 500.

${ }^{3}$ Como lo sostiene Adriana Wagmaister, "nos encontramos hoy -como resultado de las nuevas técnicas para la procreación - ante nuevas formas de paternidad y maternidad que revelan la escisión de facetas otrora unidas". Famá, Marí Victoria, La filiación. Régimen constitucional, civil y procesal, Buenos Aires, Abeledo Perrot, 2009, p. 52. ${ }^{4} \mathrm{Al}$ respecto Claudia Moran de Vicenzi señala: "La aparición y desarrollo de las diversas técnicas de procreación humana -como es la aparición de la fecundación artificial, que comprende tanto la inseminación artificial como la fecundación in vitro- ha cuestionado la vigencia de algunos principios del Derecho de Familia y el contenido del propio concepto de filiación, comenzando por los conceptos de paternidad y maternidad". Véase MoRAn DE VICENZI, CLAUDIA, El concepto de filiación en la fecundación artificial, Lima, ARA, 2005, p. 25.

${ }^{5}$ Krasnow, Adriana N. Pruebas biológicas y filiación, Rosario, unR, 1996, p. 49 y ss.

${ }^{6}$ Krasnow, Adriana N. "La filiación y sus fuentes", La Ley, 2005-A, p. 1458.
} 
ducción asistida en cuyo establecimiento ${ }^{7}$ ha de primar la voluntad; no manda lo genético, manda lo querido.

La filiación es el deseo y la intención de los partícipes, que anhelaron ser padres unos y colaboradores otros, lo cual debe primar y respetarse. Debe asemejarse al sistema de la adopción, cuya esencia radica no en la génesis (ADN) sino en la voluntad. La filiación por técnicas de reproducción asistida deja de lado lo biológico para crear un tipo de filiación por socioafectividad, sustentada en la voluntad procreacional. Ello implica una nueva fuente de la filiación. El tratamiento de la determinación de la filiación precisa claridad en ciertos conceptos que han ido evolucionando como consecuencia del avance científico.

\section{Procreación y filiación}

La aspiración de todo ser humano a la paternidad y las posibilidades que ofrecen las técnicas de fecundación artificial han llevado a defender la existencia del derecho a procrear o derecho a la procreación humana. La facultad de la persona para elegir el medio de procrear, ya sea la unión sexual o la utilización de las técnicas de reproducción, es una manifestación de este derecho.

La procreación natural es un acto biológico, tan humano, que implica la participación conjunta de un hombre y una mujer (pro-crear). Dos engendran a uno. Ese uno necesita conocer a esos dos, o a uno de los dos. Mis orígenes, mis padres, mis raices, nada como sentirse identificado con los ascendientes que nos dieron la vida. Pero, la unión sexual, la procreación natural y la veracidad de la madre fueron destronadas por la procreación asistida.

Un sector de la doctrina se ha aferrado a la idea de que existe un derecho a la procreación derivado de varios derechos fundamentales, como son el derecho a la vida, el derecho a la integridad física y a la libertad. Esta afirmación concibe un derecho a procrear como el alcance mismo de la libertad personal. El criterio de Miranda Luna va en esta línea, en el entendido de que

como derecho que se reconoce a todo ser humano, incluso contemplado

112 a nivel constitucional, se encuentra el derecho a constituir su propia familia,

\footnotetext{
${ }^{7}$ Azpiri, critica el postulado "la filiación puede tener lugar por naturaleza, mediante técnicas de reproducción humana asistida o por adopción", establecido en el artículo 558 del Proyecto de Código Civil argentino, 2012. Considera que no es la técnica de reproducción humana asistida la fuente de la filiación sino la voluntad de las partes cuando no existe coincidencia genética entre las personas que desean asumir el vínculo filial con quien ha nacido a través de esas técnicas. La fuente de la filiación que debe consignarse en el mentado artículo 558, junto con la naturaleza y la adopción, es la voluntad procreacional, en el caso de técnicas de reproducción humana asistida realizadas con material heterólogo. Cfr. AzPIRI, Jorge 0, "La filiación en el Proyecto de Código Civil y Comercial", Revista de familia y las personas, julio, 2012, vol. 4, No. 6, p. 115 y ss.
} 
no parece que haya viso alguno que para poder optar a uno de los métodos de fertilización asistida se vaya a instituir como requisito previo que la iniciativa y solicitud sea formulada por parte de una pareja matrimonial o, en su caso de convivientes declarados, imposibilitados por causas exclusivamente biológicas para procrear por vía natural. ${ }^{8}$

La filiación es consecuencia de la reproducción. Esta puede ser natural o asistida. El primer caso no presenta mayores problemas, salvo los referidos a la determinación de la filiación extramarital que hoy se solucionan con el ADN. La reproducción asistida es la que genera inconvenientes, en muchos casos, se condicen con los planteamientos legales tradicionales y con el biologismo imperante.

La tendencia actual es que el aporte de la ciencia genética en la determinación biológica de la paternidad con el ADN se aplique exclusivamente a la filiación por naturaleza (por procreación natural). Mientras, la voluntad y el afecto (socioafectividad) son la base para la filiación derivada de técnicas de reproducción asistida -como lo ha dado a entender un criterio de nuestra Corte Suprema-, ${ }^{9}$ a simili de la adopción.

Esto es que el régimen de filiación debe sustentarse en el principio de veracidad (favor veritatis), el principio de igualdad, el principio de protección de los intereses del hijo (filii) y en la voluntariedad. Y es que entre la pareja sometida a estas técnicas y el niño surge una relación socioafectiva, llena de amor, afecto y bondad, más allá de los límites del vínculo biogenético.

La pareja abdica la conexión biológica con el niño por el deseo único de llevar a cabo su proyecto parental. Se establece el vínculo emocional de paternidad, un vínculo que, como ocurre en la adopción, es irrevocable y tanto más natural que el derivado del engendramiento.

Se debe enfatizar en la socioafectividad que se forjará con la relación padre-hijo, y anteponer el factor crianza a los lazos biológicos. El desarrollo del hijo en el seno de la familia, en conjunto con los padres que lo desearon por medio de la técnica asistida, construye lazos más fuertes que los biológicos. El amor y el afecto se irán incrementando al pasar de los años. Hijo y padres se unirán de forma innegable y forjarán un vínculo difícil de romper, creando verdaderamente una familia, en el más amplio sentido de la palabra. Una familia derivada de la ciencia pero (re)fundida en el amor.

\footnotetext{
${ }^{8}$ Miranda Luna, Raúl E., Bioética y Derecho de familia: problemas actuales sobre filiación y responsabilidad, Bogotá, Universidad del Externado de Colombia, 2002, p. 300.

${ }^{9}$ Corte Suprema de Justicia de la República, Caso No. 563-2011, Lima, 2011. Disponible en https://scc.pj.gob.pe/wps/wcm/ connect/53f1df80469c5c91b51bfdac1e03f85e/CAS\%2B563-2011.pdf?MOD=AJPERES\&CACHEID=53f1df80469c5c91b51bfdac1e03f85e
} 
La filiación por técnicas de reproducción asistida se afianza en la socioafectividad y debe apreciarse como un reconocimiento del derecho fundamental a la felicidad, ${ }^{10}$ sin distinguir si se trata de pareja heterosexual u homosexual. Debe reconocerse como principio derivado de la dignidad de la persona humana, de su libertad, autodeterminación, igualdad, intimidad, no discriminación y del pluralismo que inspira a la familia moderna.

\section{Determinación de la filiación}

La determinación de la filiación consiste en su establecimiento jurídico con adecuación a su fundamento natural: la procreación. Ésta es el presupuesto biológico fundamental en la relación jurídica paterno filial. Sin embargo, esta relación puede constituirse sin hecho biológico (filiación sin procreación: adopción); existir hecho biológico y no filiación (procreación sin filiación: expósitos) o no existir una procreación y una filiación por establecerse (reproducción asistida y filiación indeterminada).

El problema surge cuando se intenta correlacionar el vínculo biológico con el jurídico. Mientras el biológico es natural, ilimitado y reservado en su determinación, el jurídico es creado, limitado y concreto en su establecimiento. Hasta cierto punto, como vemos, se contraponen.

En los supuestos de fecundación asistida con intervención de terceros (heteróloga), la filiación se determina a favor del varón o la mujer que, sin haber aportado sus gametos, consiente que su pareja recurra a aquella técnica para después del nacimiento asumir la paternidad o maternidad del nacido. Con ello, se produce una disociación entre la paternidad y maternidad biológica o genética y la filiación establecida por ley. Como consecuencia de aquella separación (del dato biológico y el vínculo jurídico), y para adecuar las normas jurídicas a las pretensiones de quienes recurren a esta clase de técnicas, se establecen dos grandes excepciones al principio de veracidad: inimpugnabilidad de la filiación y anonimato del cedente.

Vale decir que la fecundación heteróloga que se practica con conocimiento y consentimiento del marido lo inhabilita para demandar ex post por impugnación de la paternidad. Lo contrario sería entorpecer y negar sus propios actos, venire contra factum proprium non valet. En el establecimiento de la filiación

\footnotetext{
${ }^{10}$ El derecho a la felicidad consta en el preámbulo de la Declaración de Independencia de los Estados Unidos del año 1776 en las palabras de Thomas Jefferson: "Consideramos estas verdades como evidentes por si mismas, que todos los hombres son creados iguales, dotados por el Creador de ciertos derechos inalienables, que entre estos está el derecho a la vida, la libertad y la procura de la felicidad".
} 
debe primar la buena fe conjugada con la voluntad primigenia de permitir la fecundación con material genético de un tercero en la relación matrimoanial.

En cambio, en relación al anonimato del cedente, algunos señalan que el hijo tiene derecho a conocer la identidad de sus progenitores. Argumentan que este derecho está ligado con la dignidad y el derecho de conocer el origen biológico, lo cual es natural y lo más deseado por una persona. Por el contrario, la otra postura señala que el derecho de conocer la identidad del cedente constituiría una fuente de litigios, crearía incertidumbre en las parejas que recurrieran a esta práctica y violaría el derecho a la privacidad. Incluso, entre médicos y personal sanitario, existe la opinión generalizada de que el anonimato del cedente es una condición sine qua non para que exista donación de gametos.

El derecho a conocer la identidad propia es la facultad del ser humano, sustentada en el principio de la verdad biológica, que le permite saber quién es su progenitor quien, por distintas causas, puede ser desconocido, estar en discusión o ser debatible. Las profesoras Kemelmajer, Herrera y Lamm ${ }^{11}$ formulan la teoría de que no se debe privar a la persona nacida mediante técnicas de reproducción humana asistida del derecho a conocer su origen genético. La persona debe tener acceso a dicha información mediante un trámite judicial en el cual encuentre protección a los intereses involucrados (los del cedente), todo a la luz del principio de proporcionalidad.

\section{Principio biológico}

El principio biológico se sustenta en la verdad biológica: transferencia de genes entre progenitores y generados, favor veritatis. ${ }^{12}$ Utiliza el presupuesto biológico o genético de la filiación, dejando de lado el aspecto social. El sistema legal tiende a ello, favoreciendo la determinación de la filiación conforme a la realidad biológica. ${ }^{13}$ Se sustenta en el vínculo biológico, el ADN.

\footnotetext{
${ }^{11}$ Kemelmajer de Carlucci, Aida; Herrera, Marisa y Lamm, Eleonora, "Filiación derivada de la reproducción asistida. Derecho a conocer los orígenes, a la información y al vínculo jurídico", La Ley, octubre, 2012, No. 189, p. 1.

${ }^{12}$ Moran de Vicenzi señala que uno de los principios fundamentales del derecho de filiación, denominado favor veritatis, supone que el vínculo paterno filial se establece una vez comprobada la descendencia genética o biológica del nacido respecto a un varón y una mujer determinada. La importancia del favor veritatis y del derecho a conocer el propio origen biológico se fundamenta en la protección de los intereses del hijo y en el cumplimiento de los deberes de los padres respecto a sus hijos, salvo en aquellos casos excepcionales considerados por el legislador. Cfr. MorÁn DE VicenzI Claudia, El concepto de filiación en la fecundación artificial, Lima, ARA, Lima, 2005, pp. 30 y 61.

${ }^{13}$ La postura que asume Moran Vicenzi y defienden autores como Soto La Madrid y Coviello, sostiene que el elemento biológico es el factor subyacente de la filiación. Ello no supone el desconocimiento del importante papel que tiene la voluntad en la Constitución o modificación de la relación jurídica paterno filial. Más bien trata de establecer
} 
El principio voluntarista se sustenta en la verdad formal, favor affectionis. Es la verdad social representada en la posesión de estado, conocido como la verdad sociológica o el vínculo socioafectivo. El consentimiento, deseo y afecto marcan la obligación y responsabilidad de las personas que autorizaron la técnica de procreación quienes no pueden negar, luego, su compromiso biológico. ${ }^{14}$ La base es el principio de buena fe-lealtad y en la doctrina de los actos propios que son aplicadas en el derecho de familia, en razón de las relaciones de confianza que deben prevalecer entre los cónyuges, convivientes y familiares. ${ }^{15}$

La voluntad procreacional, a decir de Sambrizzi, ${ }^{16}$ es el elemento central y fundante para la determinación de la filiación cuando ésta se ha producido por técnicas asistidas de procreación. Según Medina y Roveda, ${ }^{17}$ es la filiación que surge de la intención de ser padres independientes del nexo biológico y es una de las consecuencias de reproducirse sin sexo.

El principio voluntarista se sobrepone a la verdad biológica, considerando que esta no es un valor absoluto, si se toma en cuenta las relaciones fácticas y el deseo de las partes. Favor affectionis vs. favor veritatis. Prima la voluntad y la responsabilidad, reafirmándose al "padre de derecho".

La teoría de la voluntad procreacional tiene en Díaz de Guijarro su principal exponente, quien en uno de sus trabajos sostiene que "en el caso de la inseminación heteróloga, cuando el semen es proporcionado por un extraño, también encontramos la voluntad procreacional, porque el marido que consiente semejante procedimiento asume las consecuencias jurídicas del mismo y, por eso, la calidad jurídica de padre". ${ }^{18}$

Esta teoría apunta a la determinación de la filiación con fundamento en la voluntad de querer tener descendencia, independientemente de la existencia o no del nexo biológico, el cual queda sin cuidado. Autorizada la técnica, la filia-

su verdadera función. Por ello, antes de recurrir a complicadas e inciertas interpretaciones, lo más conveniente es modificar las normas jurídicas que permitan brindar una solución adecuada a las nuevas situaciones planteadas. Cfr. Morán De Vicenzi Claudia, El concepto de filiación en la fecundación artificial, Lima, ARA, Lima, 2005, p. 89.

14 La doctrina no tiene un criterio unánime sobre el concepto voluntariedad ni de su fundamento como presupuesto determinante de la relación de paternidad. En opinión de algunos juristas, es una consecuencia del principio de la responsabilidad por actos propios. Otros, lo identifican con la voluntad de procrear. Una tercera postura, lo equipara con la voluntad de asumir el vínculo jurídico de filiación. Finalmente, algunos lo relacionan con una exigencia del deber de solidaridad. Cfr. Morán De VicenzI Claudia, El concepto de filiación en la fecundación artificial, Lima, ARA, Lima, 2005, p. 81.

${ }^{15}$ Madaleno, Rolf, Curso de direito de família, Rio de Janeiro, Forense, 2015, p. 571.

${ }^{16}$ Sambrizzl, Eduardo A., La filiación en el Código Civil y Comercial la procreación asistida, Buenos Aires, La Ley, 2016, p. 68.

${ }^{17}$ Medina, Graciela y Roveda, Eduardo Guillermo, Manual de Derecho de familia, Buenos Aires, Abeledo Perrot, 2016, p. 514.

${ }^{18}$ KaAsnow Adriana N. Filiación: Determinación de la maternidad y paternidad, La Ley, p. 219. 
ción se determina no por las pautas de la naturaleza sino por la declaración de voluntad, la cual debe constar en un documento indubitable (consentimiento informado previo, informado y libre). ${ }^{19}$

De acuerdo a la tesis de la voluntad procreacional, el régimen de filiación reconoce, implícitamente, la existencia de un elemento voluntario subyacente en la relación de paternidad, de tal importancia, que se puede llegar a su determinación al margen del dato biológico. En ese sentido, se dice que para la atribución de la paternidad es precisa la voluntad del hombre de tener un hijo con una mujer, la cual, a su vez, desea ser fecundada con el semen de aquel o de un tercero.

No es posible atribuir la paternidad en cabeza de quien, sabiendo y aceptando que su semen sirva a la fecundación, se ha limitado a ponerlo a disposición de terceros, como sucede con los cedentes, quienes no adquieren responsabilidad alguna. Sólo prima su interés altruista y solidario de permitir la paternidad de los otros. Así, la voluntad procreacional es el eje para la determinación de la filiación, con total independencia de si el material genético pertenece a las personas que, en efecto, tienen la voluntad de ser padres o madres, $o$ de un tercero ajeno a ellos. ${ }^{20}$

Desde esta perspectiva, la evolución en materia de filiación puede sintetizarse de la siguiente manera: del inicial favor legitimitatis se pasó al favor veritatis, mientras hoy se asiste al predominio del favor affectionis como criterio prevalente de constitución de la relación paterno filial. La fecundación artificial heteróloga da origen al statuts filationis ulteriore de carácter intermedio entre la biológica y la adoptiva, determinada sobre la bases de factores sociales y psicológicos.

La verdad formal se aplica en la procreación asistida heteróloga en la cual se prefiere la intención frente a la sangre. Por tratarse de una forma de procreación asistida, la voluntad de la pareja puede llegar a jugar un papel no sólo de cierta importancia sino preponderante en la determinación de la filiación. La pregunta latente y de siempre es: ¿Cuál debe tenerse en cuenta?

La filiación se determina a favor de aquel que, sin aportar sus gametos, asiente que su pareja recurra a la técnica de reproducción. Existe una disociación entre la paternidad y maternidad biológica y la filiación legalmente establecida. Fundado el vínculo filial en la voluntad procreacional compartida entre marido y mujer, deben adoptarse criterios que se ajusten a la misma por el

\footnotetext{
${ }^{19}$ Como lo manda el artículo 562 del Código Civil y Comercial argentino.

${ }^{20}$ Kemelmajer de Carluccl, Aida; Herrera, Marisa y lloveras, Nora, Tratado de Derecho de Familia (Según el Código Civil y Comercial de 2014), tomo 2, Santa Fe, Rubinzal-Culzoni, 2014, p. 508.
} 
camino de la ejemplaridad, perdiendo importancia la verdad biológica. ${ }^{21}$

Para adecuar las normas legales a los requerimientos de los usuarios se consideran dos excepciones al principio de veracidad: anonimato del cedente e inimpugnabilidad de la filiación.

\section{Procreación asistida y filiación}

En la actualidad, la procreación asistida es un tema que no se encuentra adecuadamente regulado en los países latinoamericanos. Se requiere el establecimiento de directrices jurídicas que sirvan para orientar el desarrollo de la legislación de la materia; sin embargo, la jurisprudencia ha marcado ciertos hitos y la doctrina ha fijado ciertos parámetros.

En el sistema de filiación común tradicional, la paternidad se sustenta en la verdad genética y la maternidad en la verdad biológica. En el hombre la atribución radica en el aporte de material genético y en la mujer el hecho de parir. El fin de las técnicas de reproducción asistida es permitir descendencia a las parejas estériles. Por ello, deben tener apoyo en un sistema de atribución de la filiación eficiente que no imponga, sino que construya la filiación de los concebidos y nacidos por estos medios.

En los supuestos de fecundación artificial con intervención de terceros, la filiación se determina a favor del varón o la mujer que, sin haber aportado sus gametos, consienten que su pareja recurra a aquella técnica, asumiendo la paternidad o maternidad.

Se producirá una disociación entre la paternidad y maternidad biológica o genética y la filiación legalmente establecida. ${ }^{22}$ Así, vemos que el esquema típico de la filiación no responde a las necesidades de la procreación asistida, a contrario sensu, la complica más, la altera. Aquí verificamos que no siempre hay coincidencia entre el aspecto biológico y el legal.

En el reparto autónomo que se desarrolla entre el equipo médico y la pareja, intervienen elementos ajenos, como el material genético del tercero dador. 118 Sin embargo, este último no forma parte de la relación intersubjetiva, puesto

\footnotetext{
${ }^{21}$ Kemelmajer de Carluccl, Aida; Herrera, Marisa y Lloveras, Nora, Tratado de Derecho de Familia (Según el Código Civil y Comercial de 2014), tomo 2, Santa Fe, Rubinzal-Culzoni, 2014, p. 281.

22 La fecundación artificial de carácter heteróloga ha supuesto un cambio en los modos de determinar la paternidad y la maternidad sobre la base del elemento voluntario. Un importante sector de la doctrina defiende que el consentimiento juega un papel preponderante en la determinación de la filiación sobre el presupuesto biológico y, por tanto, es posible inducir la existencia de un principio que denominan favor affectionis. Su aplicación se puede extender a la determinación de la filiación de los nacidos en virtud a esta técnica. Cfr. Morán De VIcenzI CLaudia, El concepto de filiación en la fecundación artificial, Lima, ARA, Lima, 2005, p. 68.
} 
que carece de interés en la formación de una nueva vida mediante el aporte de sus células germinales. ${ }^{23}$ Aquí surge el efecto: querer ser padre o querer ayudar a ser padre.

Las excepciones al principio de veracidad (la regla de la inimputabilidad de la filiación y el principio del anonimato del cedente) surgen como consecuencia de aquella separación entre el dato biológico y el vínculo jurídico, para adecuar las normas jurídicas a las pretensiones de quienes recurren a esta clase de técnicas. Un sector del derecho comparado tiende a la prevalencia de la voluntad, desplazando lo que mandan los genes. Esta corriente busca distinguir la filiación de los hijos nacidos por asistencia médica, haciéndola inatacable a pesar de la falta de relación entre lo biológico y lo legal. Es la voluntad la que prima y, además, la robustece.

En la fecundación asistida, la voluntad desempeña un papel relevante, por lo cual puede interpretarse:

\begin{tabular}{|l|l|l|}
\hline Procreación con voluntad & Natural & TERAS \\
\hline Procreación sin voluntad & Excepcional & Violación \\
\hline
\end{tabular}

Las técnicas de fecundación artificial con intervención de cedentes tienen por finalidad sustituir el material genético de la pareja o, en su caso, el acto gestacional. El interés no se centra en la realización del acto de procrear sino en la voluntad. Ésta actúa como causa eficiente del origen del nuevo ser, es la razón y motivo determinante para su establecimiento. La causa es aquello que determina la paternidad en la fecundación asistida.

La filiación civil, también llamada filiación social, ${ }^{24}$ filiación socioafecti$\mathrm{va}^{25}$ o filiación tecnológica, ${ }^{26}$ es contraria a la filiación por naturaleza y contiene conceptos nuevos sustentados en el deseo y en la vida de relación. Se fundamenta en la generación y la voluntad de los participantes. Voluntad de

\footnotetext{
${ }^{23}$ Krasnow Adriana N. Filiación: Determinación de la maternidad y paternidad, Buenos Aires, La Ley, p. 217.

${ }^{24}$ Pereira, Calo Mário Da Silva, Instituições de Direito Civil, tomo 5, Río de Janeiro, Forense, 2004, p. 312.

${ }^{25}$ Da Cunha Perelra, Rodrigo, Diccionario de Direito de familia e Sucessões: Ilustrado, São Paolo, Saraiva, 2015, p. 337.

26 "A plena possibilidade de atestar a verdade biológica, em percentuais elevados de confirmação da paternidade pela via do exame de DNA, traduz consigo mesma um paradoxo: a verdade biológica pode não expressar a verdadeira paternidade. Cogita-se, então, que, mesmo sem desprezar o conteúdo biológico, passa-se a uma filiação totalmente baseada na teoria da afetividade. 0 elemento sanguíneo, que por longo espaço de tempo serviu de alicerce para a constituição da relação de filiação, cede espaço para aquilo que poderiamos chamar de filiação tecnológica." Ferreira de Lira, Daniel y Braga de Soares Carvalho, Dimitre, "O material humano criopreservado e a filiação tecnológica: um debate em torno da filiação no Direito de Família", Jus Navigandi, agosto, 2012, vol. 17. [Consulta: 9 de agosto, 2012]. Disponible en $h t t p: / / j u s . c o m . b r / r e v i s t a / t e x t o / 22347$
} 
procrear, de recibir gametos, por un lado, y voluntad de no asumir una relación paterno filial; sólo de aportar gametos o de gestar, por el otro.

La típica paternidad pierde fuerza. El progenitor y sus genes son desplazados por el padre con base en su afecto, amor y comprensión; ya no más conceptos cargados de biologismo. A partir de ahora, deben primar las categorías sociológicas y culturales. Dejo de lado el institucionalismo para tender a la construcción social de la filiación.

La paternidad es un concepto social que trasciende a lo biológico. La descendencia corresponde a aquellos que la desearon. El régimen de la filiación para las técnicas procreativas se asemeja a la adopción, dado que ambas se sustentan en la voluntad, no en el dato biológico. Como en la adopción, la paternidad es totalmente espontánea, carente de cualquier vínculo de sangre. La relación entre padres e hijos se establece sobre una opción voluntaria, según el afecto entre los sujetos y, por tanto, debe considerarse legítima y verdadera relación de los padres en caso de conflictos relativos a la determinación de la paternidad.

Hay una relación lógica entre la adopción y las técnicas asistidas. La adopción se constituye como una institución jurídica en la cual se considera padres a aquellos que son así reconocidos por la ley. Nace de un acto voluntario, premunido de un afecto. De igual manera debe considerarse la paternidad derivada de las técnicas asistidas, ya que contiene elementos similares a la adopción. La diferencia radica en el uso de la ciencia médica, pero en ambos casos da nacimiento a una familia afectiva.

Cabe la siguiente interrogante: ¿Qué hacer? a) Crear una nueva categoría de filiación con base en la procreación asistida; $b$ ) adaptar la filiación a los modelos existentes. La primera gana cada vez más adeptos y se presenta como una labor apremiante, considerando que las técnicas de procreación exigen nuevas reglas de filiación, sea a través de la paternidad real o formal. No obstante, parece que el segundo criterio es más seguro, por lo cual la doctrina clásica trata de adaptarla.

En el sistema tradicional, la filiación depende básicamente del matrimonio, de la determinación biológica o de la paternidad socialmente aceptada, desconociendo el querer, que es la motivación de las prácticas de generación asistida. En la reproducción natural, la falta de voluntad del hombre para procrear es irrelevante, mientras que en la reproducción asistida es la base. En esta línea, Moran de Vicenzi ${ }^{27}$ considera que la fecundación artificial, en especial la hete-

\footnotetext{
${ }^{27}$ Morán De Vicenzi Claudia, El concepto de filiación en la fecundación artificial, Lima, ARA, Lima, 2005, p. 68.
} 
róloga, ha supuesto un cambio en los modos de determinar la filiación sobre la del elemento voluntario.

Un sector importante de la doctrina estima que el consentimiento juega un papel preponderante en la determinación de la filiación sobre el presupuesto biológico. Por tanto, es posible inducir la existencia de un principio dominado favor affectionis, cuya aplicación se haría extensible a la determinación de la filiación de los nacidos en virtud de estas técnicas.

\section{Anonimato de la cesión y el derecho a conocer nuestro origen}

Se impuso como regla el historial clínico de los usuarios de técnicas procreativas, el proceso de selección de cedentes y que la información del Registro Nacional de Cedentes fuera recogida, tratada y custodiada en la más estricta confidencialidad. Esto con el fin de conseguir una suerte de inmunidad parental (principio de anonimato).

Pero este tratamiento no es uniforme. Suecia permite conocer la identidad del cedente y España la limita, pues se considera que los hijos tienen derecho a obtener información general de los cedentes. Esta información no incluye su identidad y corresponde el mismo derecho a las receptoras de gametos y pre embriones. ${ }^{28}$

Las legislaciones comparadas han otorgado diversos tratamientos a la protección del anonimato del dador, pues consideran la participación de un tercero, dador de material genético, en el proceso reproductivo y en la determinación de los vínculos filiales. España, Francia, Grecia y Noruega regulan el anonimato. Austria y Suecia admiten el derecho de los hijos a conocer a su progenitor biológico. Alemania e Inglaterra, si bien no lo han regulado expresamente, lo han admitido a través de los Tribunales. La corriente es descartar la reserva de la identidad para desterrar el padre anónimo.

La reserva de la información no se trata de un límite total, es sólo parcial. El hijo tiene el derecho de conocer su origen, a fin de permitir la formación de su personalidad, hacerse de una identidad, con independencia del establecimiento filial. Se debe reconocer que el acto de cesión de gametos no implica

\footnotetext{
${ }^{28}$ Las legislaciones que desarrollan este tema se agrupan en dos corrientes. La primera, conformada por Alemania, Austria, Reino Unido, Suecia y Suiza, permite la aplicación de las técnicas de reproducción asistida sólo si se respeta la dignidad de las personas. Es decir, se acepta la donación de esperma y óvulos y se reconoce al hijo el derecho a conocer la identidad del donante anónimo. La segunda, conformada por Bulgaria, España, Francia, Noruega y Quebec, admite la aplicación de las técnicas de reproducción, pero no reconoce al hijo posibilidad alguna de conocer la identidad de los donantes, sólo en forma excepcional. Véase Famá, Maria Victoria, La filiación. Régimen constitucional, civil y procesal, Buenos Aires, Abeledo Perrot, 2009, p. 419.
} 
una responsabilidad procreacional, pues en ese caso no es la voluntad el deseo que sustenta la práctica. ${ }^{29}$

La interrupción del anonimato se aplicará para tres fines: $a$ ) impedimentos matrimoniales; $b$ ) para satisfacer una necesidad psicológica de conocer la ascendencia genética; c) para preservar y salvaguardar la vida y la salud del niño, y sus padres, en caso de enfermedad genética o hereditaria.

\section{Tipos de fecundación}

La inseminación artificial homóloga es la que manipula los gametos de la mujer (óvulo) y del marido (semen). La manipulación, que permite la fecundación, implica sustituir a la concepción natural. Este medio artificial resulta de la imposibilidad o de la deficiencia para engendrar de uno o de ambos cónyuges. María Victoria Famá sostiene que: "La inseminación homóloga se practica en los casos en que, a pesar de ser ambos progenitores fértiles, la fecundación no es posible a través del acto sexual, por diversas causas, tales como la impotencia del hombre o el vaginismo de la mujer, trastornos endocrinos o del metabolismo, secesiones vaginales que neutralizan los espermatozoides, alteraciones del cuello del útero". ${ }^{30}$

Esta práctica no crea mayor problema en la determinación de la filiación puesto que existe un vínculo matrimonial que le otorga seguridad jurídica a la descendencia en base a la presunción pater est y a la determinación de la maternidad por el parto. Cuando el semen proviene del marido, la realidad biológica del niño coincide con el presupuesto legal que origina la presunción de paternidad. ${ }^{31}$

Así existe una perfecta coincidencia entre la verdad biológica y la verdad jurídica con lo cual no existe obstáculo para que el hijo nacido de la fecundación artificial homóloga del genitor unido en matrimonio consiga el status de hijo matrimonial. ${ }^{32}$ Consideramos que alcanza, también, a los convivientes, a las parejas estables, pues ofrecen una presunción legal de paternidad respecto del conviviente de la mujer.

\footnotetext{
${ }^{29}$ María Victoria Famá sostiene que: "la ponderación de los derechos en juego exige adoptar una solución intermedia que, por un lado, garantice el derecho a la identidad del hijo y, por el otro, preserve los vínculos familiares habidos de la fecundación heteróloga, siendo en tal caso necesario 'sacrificar' en cierta medida la intimidad del donante. Esta solución implica, necesariamente distinguir entre dos aspectos del derecho a la identidad: el derecho al emplazamiento filial y el derecho a conocer los origenes". Véase FAmÁ, Marí VICTORIA, La filiación. Régimen constitucional, civil y procesal, Buenos Aires, Abeledo Perrot, 2009, p. 427.

${ }^{30}$ Famá, Maria Victoria, La filiación. Régimen constitucional, civil y procesal, Buenos Aires, Abeledo Perrot, 2009, p. 110.

${ }^{31}$ Famá, Maria Victoria, La filiación. Régimen constitucional, civil y procesal, Buenos Aires, Abeledo Perrot, 2009, p. 110.

32 Sesta, Michele, "Filiazione", en Enciclopedia del Diritto, Aggiornamento, tomo 4, Milán, Giuffré, 2002, p. 596.
} 
Por su parte, la fecundación heteróloga es la fecundación supraconyugal. Se realiza con gametos de ajenos a los cónyuges, i.e. de terceros, cedentes -mal llamados donantes-. El matrimonio es una institución cerrada en la cual se consagra los fines de la familia y donde nacen los hijos. Cuando un cónyuge es infértil, se recurre a un tercero para que ceda sus gametos, con lo cual surgen diversos problemas, de orden personal, de pareja y, principalmente, de nexo filial.

Crea situaciones inseguras, puesto que no hay una relación jurídica reconocida para exigirle al cedente el cumplimiento de obligaciones legales (alimentos), derechos derivados (transmisión sucesoria), deberes naturales (reconocimiento), negación de vínculos filiales (impugnación de paternidad), conculcación de derecho a la identidad (origen biológico disociado), entre otros. Ello ocasiona una divergencia entre el favor veritatis y el favor legitimatis, lo biológico se contrapone a lo legal. ${ }^{33}$

La cesión de material genético implica tanto los productos biológicos del hombre (espermatozoides) como de la mujer (óvulos) y encuentra su fundamento en la libre disposición de los derechos de las personas, el derecho de fundar una familia, el derecho a procrear, la igualdad y libertad.

En gran medida, esta forma de procreación deja de lado la adopción. En todo caso, ésta ya no es una opción para tener hijos, por lo cual es desplazada. Mediante este tipo de técnica, los hijos, de forma parcial, son más cercanos a “mi naturaleza”. En cambio, los adoptivos no tienen nada de la pareja adoptante. De este modo, el duelo genético, el no poder transferir nuestros genes, es menos doloroso.

Cuando los gametos empleados son de terceros se produce una disociación entre la paternidad legal y la biológica. Se rompe con el principio tradicional de la determinación de la filiación. Se parte del principio de que el nacido de estas técnicas es hijo de la mujer que lo da a luz y del marido o conviviente, siempre que exista consentimiento.

La doctrina reconoce la gran problemática referida a este tipo de reproducción asistida. Por utilizar células reproductivas de un tercero, extraño a la pareja, presenta mayores discusiones jurídicas en torno a sus consecuencias dentro del arraigo familiar. No podría ser diferente, dado que en esta hipótesis la filiación no será regida por el dogma biológico, y las presunciones de legitimidad filial, sino por un aspecto superior, fundado en lazos de afectividad.

Una de las cuestiones que se debate es cómo asegurar la filiación del hijo. Al discutirse su admisibilidad, se corre el riesgo de quedarse sin un entron-

\footnotetext{
${ }^{33}$ Sesta, Michele, "Filiazione", en Enciclopedia del Diritto, Aggiornamento, tomo 4, Milán, Giuffré, 2002, p. 597.
} 
camiento filial claro. Como refiere Azpiri, ${ }^{34}$ "la verdadera cuestión referida a la filiación se presenta cuando ha mediado una técnica de procreación con material total o parcialmente heterólogo, en razón que en dicho supuesto, al no coincidir el aporte genético con la pretensión de establecer el vínculo filial, pasa a cobrar importancia la voluntad procreacional".

El derecho parte del principio de que son hijos extramatrimoniales los concebidos y nacidos fuera del matrimonio. Éste queda desfasado como consecuencia de las modernas técnicas de reproducción asistida, el congelamiento de material genético y la crioconservación de embriones. A la fecha, puede concebirse un hijo dentro del matrimonio, crioconservarse y ser implantado luego de disuelto el vínculo, incluso después de transcurrido el plazo de 300 días. La implantación post matrimonial altera la calidad legal y el estado civil de los hijos.

\section{Determinación de la paternidad}

La determinación de la paternidad parte de la relación jurídica del hombre y la mujer. Ésta puede estar sustentada en un matrimonio o unión estable, pues ambos actos jurídicos son fuentes de familia que consolidan la relación filial con la descendencia. Cuando nos referimos al marido, debemos considerar, también, al conviviente, a la pareja estable. Hay tres teorías al respecto:

- El consentimiento del marido determina la paternidad con carácter inimpugnable y sin posibilidad de establecer la de los cedentes;

- Con base en el interés del menor, el consentimiento del marido es similar al reconocimiento y se descarta la investigación de la paternidad del cedente pues éste no se responsabilizó de la paternidad, y;

- El consentimiento del marido es ineficaz para determinar la filiación, pudiendo determinarse la filiación del cedente.

A la luz de las teorías indicadas, se presenta una casuística variopinta. Con consentimiento del marido, no hay mayor inconveniente, pues existe una manifestación de voluntad en la realización de la técnica con material de cedente. De este modo, no se puede impugnar la paternidad, dado el consentimiento previo, con base en la teoría de los actos propios.

\footnotetext{
${ }^{34}$ AzPIRI, Jorge 0, "La filiación en el Proyecto de Código Civil y Comercial", Revista de familia y las personas, julio, 2012, p. 115 y ss.
} 
La doctrina extranjera ${ }^{35}$ ha estudiado la problemática derivada de la fecundación artificial con intervención de cedente de semen desde dos perspectivas distintas, pero estrechamente vinculadas entre sí:

- El consentimiento del marido es eficaz para establecer la paternidad y, de ser el caso, si la filiación podría llegar a ser determinada en cabeza del cedente de semen.

- Establecer los efectos jurídicos que se derivan del consentimiento sobre el ejercicio de la acción de impugnación de la paternidad.

En el supuesto de la fecundación heteróloga de la mujer casada que se efectúa con consentimiento del marido, la paternidad matrimonial quedará determinada a favor de éste, en virtud de la presunción pater est. Por ello, la doctrina ha intentado justificar qué criterio y por qué debe prevalecer al momento de determinar la filiación del nacido. Al respecto existen dos posturas:

- El consentimiento del marido para la fecundación heteróloga determina la paternidad matrimonial, excluyendo cualquier posibilidad de establecer la filiación en cabeza del cedente de semen.

- El principio del favor minoris se alega para descartar la determinación de la paternidad del cedente de semen, ya que el menor no tendría interés en determinar su filiación frente a quien, con la cesión de sus gametos, evidencia su voluntad de no querer asumir dicho vínculo paterno-filial.

Sin embargo, se han presentado algunos casos a nivel judicial que contrarían las normas del derecho de familia y la determinación de la paternidad, por ejemplo:

- Cuando existe un vicio en el consentimiento. Si hubiera coincidencia genética y matrimonio de por medio, sólo cabría una acción de daños a favor del marido, quedando la paternidad incólume.

- Error en la fecundación con semen distinto del marido. Debe conside125 rarse como padre al existir no sólo consentimiento sino, también, el acto de cesión de semen, muy a pesar de que la fecundación se haya realizado erróneamente con material de tercero. ${ }^{36}$

\footnotetext{
${ }^{35}$ Famá, Maria Victoria, La filiación. Régimen constitucional, civil y procesal, Buenos Aires, Abeledo Perrot, 2009, p. 91. ${ }^{36}$ Con este criterio Sambrizzı, Eduardo A., La filiación en el Código Civil y Comercial la procreación asistida, Buenos Aires, La Ley, 2016, p. 213.
} 
Los casos donde hay consentimiento del marido, pero después niega la paternidad, se han resuelto con base en la teoría de los actos propios, venire contra factum proprium non valet y protestatio facto contraria non valet. Se limita la impugnación de la paternidad en razón del acto contrario a la buena fe y el abuso del derecho.

La tendencia aplicable es que la voluntad procreacional inicial del marido marca su compromiso como padre en la aceptación y atención de la descendencia. Siguiendo a Sambrizzi, ${ }^{37}$ uno de los escollos de la doctrina que admite la posibilidad de la impugnación de la paternidad por parte del cónyuge es la inmoralidad en la conducta de quien se retracta luego del proceso. Esto a pesar de haber dado libremente su consentimiento para la fecundación con gametos de un tercero.

De este modo, se viola el principio de la buena fe y lealtad, que el derecho no puede desatender. Imaginemos un caso donde el padre impugna su paternidad y no puede conocerse la identidad del cedente, configurándose nada menos que un hijo de nadie, parentless. Esta situación no puede ser aceptada por el derecho.

La falta de consentimiento de uno de los cónyuges en la participación del otro como aportante (marido) o receptora (mujer) afectan las relaciones conyugales, tipificándose una causal de divorcio (adulterio o injuria grave); siendo el hijo pasible de impugnación de su filiación.

Esta situación afecta a la cónyuge y también al hijo, quien puede terminar sin padre. Por ello, es importante exigir el consentimiento del marido para la fecundación de su mujer con semen de tercero, la misma que no sólo es aplicable para la fecundación heteróloga sino, también, para la aplicación de las técnicas de procreación asistida que comprende la fecundación de la mujer con semen del cónyuge, ${ }^{38}$ como vimos ut supra.

Se puede presentar el caso de no consentimiento del marido por incapacidad. El acto procreacional se configura y legitima con base en la voluntad. La decisión de tener un hijo genera obligaciones y responsabilidades que se deben asumir de manera integral. La incapacidad del procreante limita su responsabilidad y deberá comprometerse a quien utilice indebidamente el material genético.

Otros casos que se han planteado en la doctrina y casuística son:

\footnotetext{
37 SambrizzI, Eduardo A, La filiación en la procreación asistida, Buenos Aires, UCA, 2004, p. 183.

${ }^{38}$ SambrizzI, Eduardo A, La filiación en la procreación asistida, Buenos Aires, UCA, 2004, p. 178.
} 
- Paternidad del hijo de mujer casada o conviviente fecundada sin su consentimiento con semen de cedente;

- Error en la fecundación respecto del material genético;

- Fallecimiento de los cónyuges antes de la transferencia del embrión, y;

- El caso de mujer soltera, separada legalmente, viuda o divorciada (se crearía una familia unilineal o monoparental; mejor dicho, matrilineal).

Cuando hay consentimiento del conviviente, debe realizarse el reconocimiento para atribuir legalmente la paternidad. Este caso admite la doctrina y jurisprudencia comparada de que el asentimiento de la pareja para la fecundación homóloga sea por escritura pública o testamento. Se puede consider un reconocimiento indirecto o, en su caso, un escrito indubitado a efectos de canalizar una demanda judicial de paternidad extramatrimonial.

Esto operaría como un caso de reconocimiento de un concepturus (aquel no concebido). Téngase presente que se está reconociendo a un hijo no biológico configurándose, en stricto sensu, un reconocimiento por conveniencia o por complacencia.

En caso de que no haya consentimiento del conviviente, al no existir título de estado y falta de consentimiento, la atribución de paternidad estaría negada.

\section{Determinación de la maternidad}

El principio tradicional que sigue el derecho in genus es el mater semper certa est, puesto que el parto debidamente acreditado es el hecho que atribuye de pleno derecho la maternidad. El parto sigue al vientre, partus sequitur venter, razón por la cual, la maternidad en sentido biológico es siempre cierta. Esto, como dice García de Solavagione,39 se sustenta en la suposición de que el parto culmina con el proceso iniciado con la fecundación del óvulo y desarrollado sin interrupción alguna. Así, se detecta una suerte de presunción tácita: la ley presume que la mujer da a luz al hijo que concibió con su óvulo.40

Sin embargo, las nuevas tecnologías reproductivas alteran dicho principio ante la posibilidad de que la madre gestacional no sea al mismo tiempo la madre genética. Se puede dar el caso de que el hijo que lleve en su vientre sea el resultado de la unión de la cédula germinal de su marido con la célula germinal

\footnotetext{
${ }^{39}$ Garcia de Solavagione, Alicia, "Filiación por naturaleza o biológica", en Guillermo Borda (dir.), Derecho de familia y de las personas: entre el Derecho dado y el Derecho proyectado, Córdoba, Nuevo Enfoque Jurídico, 2014, p.123. ${ }^{40}$ Artículo 409 del Código Civil peruano y artículo 565 del Código Civil y Comercial argentino.
} 
de otra mujer ${ }^{41}$ o de que albergue un ser concebido con gametos de terceros, siendo ella mera gestante.

La determinación de la maternidad es compleja, pues se vincula con prácticas de maternidad subrogada relacionadas con la cesión de gametos. Entre otras, son las siguientes. En la ovocesión, vulgarmente conocida como ovodonación, la mujer cesionaria tiene una deficiencia ovárica, no genera óvulos, pero sí puede gestar, por lo cual necesita de una mujer que sólo le ceda óvulos. Es un caso de maternidad parcial. Se produce un caso de generación múltiple (trilateral): $a$ ) espermatozoides del marido; $b$ ) óvulo de una cedente; c) gestación de la mujer cesionaria de óvulo. De este modo, la madre procreante no es la misma que la gestante.

En Perú, mediante Casación 4323-2010, Lima (11/08/2011) se ha dejado establecido que el artículo 7 de la Ley General de Salud no prohíbe la ovodonación, pues no es un procedimiento ilícito, sino sólo un tema de vacío normativo y jurisprudencial. Este pronunciamiento se emitió en el marco del recurso de casación interpuesto contra la sentencia de vista, expedida por la Sexta Sala Civil de la Corte Superior de Justicia de Lima. ${ }^{42}$ Ésta revocó la apelada que declaró, infundada la demanda de nulidad de acto jurídico y, reformándola, la declaró fundada.

Esto al considerar que la ovodonación, realizada en mérito a los documentos denominados Convenio de realización de Técnica de reproducción asistida y autorización de fertilización in vitro y transferencia embrionaria, es un procedimiento contrario a lo dispuesto en el artículo 7 de la Ley General de Salud. Sin embargo, el Tribunal Supremo sostuvo que, si bien la ovodonación es un procedimiento que no se encuentra legislado, su práctica no deviene en ilegal, en virtud al axioma jurídico de que todo lo que no está prohibido está permitido. ${ }^{43}$

Ya en el fallo anterior Casación 5003-2007, Lima (06/05/2008), el mismo órgano jurisdiccional tuvo la oportunidad de pronunciarse sobre la alegada prohibición de la ovodonación, lo cual no hizo. Por su parte, la Casación 5632011, Lima (06/12/2011), resuelve un caso de maternidad subrogada en el cual una pareja que recurrió a la técnica lleva a cabo un proceso de adopción para

\footnotetext{
${ }^{41}$ Krasnow Adriana N. Filiación: Determinación de la maternidad y paternidad, Buenos Aires, La Ley, p. 218.

${ }^{42}$ En el proceso seguido contra ella y contra el Instituto de Ginecología y Reproducción y Clínica de Fertilidad Asistida y Ginecologia Concebir, por Custodio Olsen Quispe Condori y doña María Alicia Alfaro Dávila.

${ }^{43}$ Situación que, aunada al cumplimiento de los requisitos previstos en el artículo 140 del Código Civil, determinó que se declare fundado el recurso de casación, en consecuencia nula la sentencia de vista y actuando en sede de instancia se confirme la sentencia apelada.
} 
regularizar la situación filial. Destacó que, de acuerdo al interés superior de la niña, la misma estaría mejor con ellos (demandante y recurrentes) por la intención que mostraron de ser padres. A diferencia de ellos, quienes formaban la pareja demandada en ningún momento tuvieron la intención de ser padres, pero sí de obtener una ventaja económica. ${ }^{44}$

También existe el caso de la madre sustituta, donde la mujer ni genera óvulos ni puede gestar. En éste, hay deficiencia ovárica y uterina, por lo cual debe buscar una mujer que cumpla con dichas funciones, i.e. que permita ser fecundada y termine el proceso de gestación.

Asimismo, existe el caso de maternidad integral. Se produce un caso de generación humana integral con: $a$ ) espermatozoides del marido; $b$ ) inseminación en tercera mujer; c) la madre procreante es la misma que la gestante.

\section{Maternidad subrogada}

Aparte de los dos casos antes mencionados las prácticas de maternidad asistida son más complejas y variadas. La maternidad subrogada pone de manifiesto dos dificultades preliminares: ${ }^{45}$ la confusión del problema de la regulación de la filiación con el de la regulación de la maternidad por subrogación, y el hecho de que no estén explicitadas las razones que han conducido a permitir sólo la subrogación por motivos altruistas.

Actualmente, es viable que hasta cinco mujeres puedan ser madres participando, indistintamente, en el proceso biosociojurídico. Éstas son: a) genetrix, madre genética que aporta el óvulo; b) gestatrix, madre biológica o gestacional; c) madre biogenética, que enriquece con su material genético; $d$ ) madre legal, quien adopta; $d$ ) madre social, quien cría.

El problema de la delimitación de la maternidad frente a la utilización de técnicas de reproducción asistida se presenta cuando se advierte una disociación entre la maternidad genética, la maternidad gestacional y la maternidad social.

El derecho comparado, casi unánimemente, se pronuncia sobre el tema. Indica que la maternidad del nacido corresponde a la mujer que lo ha gestado, aun cuando se demuestre que le fue implantado un óvulo fecundado de otra mujer, prohibiendo los contratos de maternidad subrogada. ${ }^{46}$

\footnotetext{
${ }^{44}$ Véase Mosouera Vásouez, Clara Celinda, "El primer caso de vientre de alquiler", Diálogos con la Jurisprudencia, agosto, 2012 , vol. 18 , No. 167 , p. 55 y ss.

${ }^{45}$ Seleme, Hugo Omar, "La maternidad por subrogación y los límites de la autonomía" La Ley, enero, 2013, vol. 77, No. 13, p. 2.

${ }^{46}$ Las legislaciones que desarrollan esta figura se agrupan en tres corrientes. La primera, conformada por Australia, Alemania, Austria, Bélgica, Bulgaria, Canadá, Chile, China, Dinamarca, Egipto, España, Francia, Gran Bretaña, Ho-
} 
Algunos países admiten la celebración de los contratos de maternidad subrogada, con el previo cumplimiento de ciertos requisitos y procedimientos. Ante la eventualidad de que surjan conflictos por incumplimiento de los contratos - por la negativa de la madre gestante a entregar al nacido-, los tribunales han resuelto mediante la aplicación del principio de interés del menor. Así, se le proporciona, en algunos casos, la adopción a la madre comitente; en otros, han determinado la filiación de los padres comitentes, reconociendo el derecho de visitas de la madre subrogada (maternidad compartida). ${ }^{47}$

En el Perú no existe una prohibición, como $a b$ initio se creía, a la fecundación extracorpórea con óvulo de cedente (ovodonación), a la transferencia de embrión ajeno (embriodonación) y, a los servicios de gestación subrogada (maternidad portadora). Supuestamente la limitación se fundamentaba en dos principios: la maternidad se prueba por el hecho del parto (artículo 409, сc), y la calidad de madre genética debe coincidir con la de madre biológica (Ley General de Salud, artículo 7).

Sin embargo, mediante la casación 4323-2010, Lima (11/08/2011), la Sala Civil Permanente de la Corte Suprema de Justicia ha dejado establecido que el artículo 7 de la Ley General de Salud no prohíbe la ovodonación, la misma que no es un procedimiento ilícito, representando más bien un vacío normativo y jurisprudencial.

Estos procedimientos sólo presentan restricciones éticas, pues contrarían instituciones jurídicas como el parentesco, la filiación, el ejercicio natural del derecho reproductivo pero, como actos médicos, carecen de sanción penal. En

landa, Italia, Japón, Portugal, Quebec, Suecia, Suiza, Taiwán y Turquia, quienes regulan esta figura como nula, la prohiben y en algunos casos, como el de Alemania, establecen sanciones penales para estas prácticas. La segunda, conformada por algunos estados norteamericanos y Grecia, la admiten a través de un acuerdo escrito entre las personas que desean procrear, validado a través de un tribunal competente que establece la filiación. En la tercera, conformada por Brasil, Ecuador y El Salvador, no existe un marco regulatorio; la maternidad subrogada se practica sin restricciones.

Brasil la admite sólo si se recurre a un miembro de la familia. Destaca la posición que sugiere el derecho latinoamericano, tal como lo señala Paulo Lôbo cuando afirma que "en el caso de la inseminación artificial homóloga, en Brasil y en la mayoria de paises, no se permite el uso instrumental del útero ajeno, sin vínculo de filiación (popularmente conocido como 'vientre de alquiler'). Con la naturaleza de la norma ética dirigida a la conducta profesional de los médicos, la Resolución № 1.358 de 1992 del Consejo Federal de Medicina admite la cesación temporal de útero sin fines de lucro, siempre que la cedente sea pariente colateral hasta el segundo grado con la madre genética". Véase LôBo, Paulo. Dirieto Civil. Familias, São Paolo, Saraiva, 2011, p. 199

${ }^{47}$ Dentro de este grupo se encuentran Reino Unido (Human Fertilization Embriology Act - 1990) que permite el recurso a la maternidad subrogada siempre que se celebre a título gratuito, bajo la supervisión de la entidad encargada de regular y el tratamiento de la infertilidad humana. 
buena cuenta son actos no arreglados a derecho, ni a la moral, pero al no estar tipificados en la ley penal no son delito, ni falta, nulla crimen, nulla poena sine praevia lege. Lo delictual se produce cuando hay fingimiento de preñez, suposición de parto, alteración de la filiación y del estado civil, falsos reconocimientos (artículos 143 a 145, cc), tendientes al tráfico de niños como se reconoce y se persigue.

La ley peruana, en especial la Ley General de Salud, no se ha pronunciado sobre la madre sustituta; es decir, cuando una mujer acepta ser inseminada con material genético del marido de otra a fin de entregar a la criatura una vez nacida. Aquí, la maternidad genética coincide con la biológica. La madre lo concibe y lo gesta, restando sólo la entrega. La prohibición indicada en la Ley General de Salud resultaría inaplicable, pues ambas maternidades guardan equidad. Lo ilícito se generaría con la vulneración del Código Civil en su norma citada (artículo 409, cc).

Muchas legislaciones, como la argentina, consideran que la maternidad corresponde a la mujer que gesta y da a luz, aun cuando se demuestre que le fue implantado el óvulo fecundado de otra. Esta tendencia se reconoce en innumerables criterios judiciales a nivel mundial. En efecto, el artículo 562 del Código Civil y Comercial argentino establece que: "Los nacidos por las técnicas de reproducción humana asistida son hijos de quien dio a luz y del hombre o de la mujer que también ha prestado su consentimiento previo, informado y libre".

Sobre el particular, es de mencionar que "Una jueza de Lomas de Zamora declaró la inconstitucionalidad (30/12/2015) del artículo del nuevo Código Civil (562) el cual dispone que los hijos gestados en un vientre sustituto son hijos de quien los dio a luz. Según el fallo, la norma no reconoce la maternidad de la mujer que ha expresado su voluntad procreacional mediante el consentimiento informado". ${ }^{48}$

Algunos países permiten la sustitución de maternidad y sus derivaciones cuando se realiza en mujeres emparentadas familiarmente (madre-hija, hermanas, tía-sobrina, primas, cuñadas) y no hay lucro de por medio. La tendencia viene redireccionándose hacia el aspecto afectivo, primando el sentir procreacional, el deseo que tuvo la mujer de gestar para otra. Frente al principio de la verdad biológica, el cual debe imperar, surge el principio voluntad procreacional. Éste parte del reconocimiento y desarrollo del principio del interés superior del niño.

\footnotetext{
${ }^{48}$ Werner, Matias, "La voluntad procreación al hace a la madre", Diario Judicial, No. 4223, [Consulta: 21 de marzo, 2016], Disponible en http://www.diariojudicial.com/nota/74754
} 
Para Sesta, ${ }^{49}$ existen tres formas de maternidad subrogada: a) donación de ovocito, es decir entrega de óvulo a un tercero; b) maternidad subrogada, es decir que, con consentimiento de su cónyuge, el marido fecunda el ovocito de una tercera mujer que gesta, pare, y entrega al menor a la pareja; c) locación de útero (affitto di ventre), cuando el embrión in vitro es colocado en el vientre de una mujer que no es genéticamente la madre, a cambio de una contraprestación dineraria.

A nuestro criterio, la maternidad subrogada puede darse en dos niveles: la madre portadora y la embriocesión. En el primer tipo, la mujer genera óvulos pero tiene una deficiencia uterina o física que le impide gestar por lo que debe buscar una mujer que colabore con ella en dicha labor biológica.

Es un préstamo de útero por lo cual se da una maternidad parcial. Se produce un caso de trigeneración humana: aporte de espermatozoides del marido, aporte de óvulo de su mujer y la madre gestante es una tercera. La doble maternidad portadora es un caso extremo, como aquel presentado en 1997, en Italia, cuando se anunció la gestación de dos fetos de parejas distintas en el útero de una misma mujer.

El segundo nivel es la embriocesión, vulgarmente llamada embriodonación. Se da cuando el problema es infertilidad completa en la pareja, por lo que deben buscar un cedente de esperma y una mujer que ceda su óvulo, o sea fecundada, y termine el proceso de gestación. Este proceso puede ocasionar un caso de multigeneración humana cuando el marido y la mujer son infértiles; el embrión es de una pareja cedente; el embrión es gestado por una tercera mujer o por la cedente del óvulo.

Por su parte, la cesión mixta o conjunta se da con la espermatocesión y ovocesión, incluso con madre portadora. Los problemas legales de orden filial se complejizan al confluir una multiplicidad de componentes biogenéticos, lo cual es una suerte de paternidad múltiple.

\section{Fecundación post mortem}

La fecundación post mortem, por su parte, es una de las técnicas de reproducción que ha despertado mayor polémica. La regla es que el uso del semen del marido sólo se permite mientras esté vivo, por ser el titular exclusivo de las partes de su cuerpo. Su aplicación es una de las más controvertidas en cuanto a la determinación de la paternidad al estar en juego aspectos y derechos que

\footnotetext{
${ }^{49}$ SeSTA, Michele, "Filiazione", en Enciclopedia del Diritto, Aggiornamento, tomo 4, Milán, Giuffré, 2002, pp. 600 y 601 , nota 200.
} 
deben ser cuidadosamente resguardados, como el derecho del niño a conocer su identidad y el respeto de la voluntad del cónyuge cuyo material genético se ha utilizado.

El desarrollo de las técnicas de fecundación, así como los métodos de crioconservación de esperma, óvulos y embriones, ha presentado serios problemas en cuanto a la filiación, matrimonial o extramatrimonial que corresponden al procreado post mortem. Si bien existe la plena certeza de la descendencia genética y de la identidad del progenitor, el nacido es hijo de una persona fallecida (hijo sin padre).

La fecundación post mortem está referida a Los hijos póstumos, es decir que fueron concebidos por el padre en vida y nacieron después de su fallecimiento, pero antes de los 300 días siguientes a la disolución del matrimonio. También los hijos superpóstumos o post póstumos, que fueron concebidos y nacieron después de la muerte del progenitor, luego de los 300 días siguientes a la disolución del casamiento, de modo que no es aplicable la presunción de paternidad.

Las técnicas de fecundación in vitro y de crioconservación de gametos permiten que la fecundación y la gestación puedan presentarse de manera discontinua. Uno de ellos está relacionado con la procreación artificial post mortem que puede darse en dos supuestos, bien cuando el marido o compañero more uxorio de la mujer fallece, en un momento anterior a la implantación de un embrión formado en vida de aquel, o bien, cuando el deceso del hombre se verifica antes de haber iniciado la fecundación.

La procreación artificial post mortem no es una práctica unánimemente admitida en el derecho comparado, ${ }^{50}$ debido a lo engorroso de sus efectos jurídicos. Además, se debe considerar que un evento fortuito no haya producido el fallecimiento luego de la concepción, porque ello se encuentra dentro de las posibilidades naturales ${ }^{51}$ sino que la concepción o implantación sea la voluntad de las partes.

\footnotetext{
${ }^{50}$ Dentro de las legislaciones que prohiben la fecundación post mortem tenemos a Noruega y Alemania que sanciona con pena privativa de libertad o sanción pecuniaria. Suiza prohíbe la utilización de gametos de una persona después de fallecido. Dinamarca dispone que, en el caso que muera el hombre, el esperma que ha sido conservado para practicar una inseminación artificial a la compañera debe ser destruido. Italia excluye como destinatarias de las técnicas de reproducción asistida a las mujeres viudas, pero el Tribunal autorizó una implantación post mortem de un embrión fecundado en vida del marido. Francia establece que el consentimiento a la fecundación asistida deja de producir efectos en el supuesto de defunción. Por su parte, España, Reino Unido, Grecia, Canadá autorizan y permiten la fecundación post mortem, previo consentimiento.

${ }^{51}$ AzPIRI, Jorge 0., "La filiación en el Proyecto de Código Civil y Comercial", Revista de Familia y las Personas, julio, 2012, vol. 4, No. 6, p. 115 y ss.
} 
Si se presenta el caso, corresponde verificar necesariamente los siguientes puntos:

- Consentimiento del cónyuge expresado en vida a fin de que el otro utilice el material genético.

- Eficacia del consentimiento luego del fallecimiento.

- Momento de la implantación y del nacimiento para efecto de establecer la filiación, sea matrimonial o extramatrimonial.

Una de las aristas en este tema es el relacionado a la atribución de paternidad, considerando el fallecimiento anticipado del padre biológico. Para muchos es el tema fundamental, debido a las consecuencias jurídicas en la filiación. La causa más compleja que está sujeta a análisis es la determinación de la filiación entre el niño nacido de esta técnica y el padre premuerto. Algunos consideran que

una novedad legal en esta primera hipótesis es la posibilidad de que la fecundación ocurra cuando ha fallecido el marido. La presunción tradicional atribuye la paternidad en relación al hijo nacido dentro de los trescientos días después de la muerte de aquel. La fecundación artificial homóloga podrá ocurrir en el tiempo posterior a la muerte de éste persistiendo la presunción de paternidad del fallecido desde que se aprobó la utilización de sus gametos por parte de la entidad en que cumplió con el almacenamiento. El principio de autonomía de los sujetos, como uno de los fundamentos del bioderecho, condiciona la utilización del material genético del fallecido al consentimiento expreso que se hubiera dado para este fin. Asimismo, la viuda no podrá exigir que la institución responsable del almacenamiento le entregue el semen almacenado para que sea inseminado, no podrá ser objeto de herencia. La paternidad debe ser consentida porque no se pierde la dimensión de libertad. La utilización no consentida del semen apenas es admisible para el donante anónimo, que no implica atribución de paternidad. ${ }^{52}$

La crioconservación significó la proliferación de estas prácticas y fue una forma de incentivar la fecundación post mortem como medio de revivir la

\footnotetext{
${ }^{52}$ LôBo, Paulo. Dirieto Civil. Familias, São Paolo, Saraiva, 2011, p. 198.
} 
muerte a través de la fecundación de un nuevo ser. En estos casos se ha optado por aplicar las siguientes reglas:

- Si el hijo nace dentro del plazo se aplica la presunción pater est, siendo matrimonial y del difunto.

- Si el hijo nace fuera del plazo debe diferenciarse si se trata de una $a$ ) inseminación (si hay certeza de la identidad genética y de la voluntad, no cabe aplicar el plazo); b) transferencia embrional, (si fue concebido durante el matrimonio se le reputa matrimonial).

- Si la fecundación es con material genético de cedente. Un sector la rechaza al no haber matrimonio, identidad genética, ni voluntad salvo que el marido consienta de manera expresa e inequívoca. Para estos efectos se toma en cuenta la voluntad procreacional hecha en vida por el marido.

La procreación post mortem lleva a establecer que el derecho a la maternidad de la viuda genera hijos sin padre, aunque se acredite el vínculo biológico. Por lo demás, generaliza la uniparentalidad o monoparentalidad.

Nada obsta que se verifique una fecundación post mortem con material genético de la mujer premuerta, $v$. g. utilización de los óvulos o embriones congelados cuando la mujer partícipe ha fallecido. La determinación de la maternidad, a simili, debe provenir de la voluntad previamente establecida.

El consentimiento es la base para la determinación de la filiación. Es una condición definitiva que debe quedar claramente establecida en los casos de la realización de fecundación post mortem. La verificación del otorgamiento del consentimiento debe ser el elemento que debe manifestarse previa y expresamente, o bien, éste puede ser razonablemente inferido para garantizar el respeto a la autonomía de la persona. En sentido contrario, el uso de material genético violaría esta regla ética, pues tomar tales decisiones por otros sería tratarlos como medios y no como un fin en sí mismo.

\section{Conclusión}

El aporte de la ciencia genética en la determinación biológica de la paternidad con el ADN debe aplicarse a la filiación por naturaleza (por procreación natural) mientras que la voluntad y el afecto (socioafectividad) debe ser la base para la determinación de la filiación derivada de las técnicas de reproducción asistida.

La voluntad procreacional se erige como la fuente en este tipo de filiación en aras de consagrar la causa que precedió a la procreación. Es decir, busca reconocer el verdadero deseo de quienes son los verdaderos padres. 


\section{Bibliografía}

AzPIri, Jorge 0, “La filiación en el Proyecto de Código Civil y Comercial”, Revista de Familia y las Personas, julio, 2012, vol. 4, No. 6, p. 115 y ss.

Corte Suprema de Justicia de la República, Caso No. 563-2011, Lima, 2011. Disponible en https://scc.pj.gob.pe/wps/wcm/connect/53f1df80469c5c91b51bfdac1e03f85e/CAS\%2B563-2011.pdf?MOD=AJPERES\&CACHEID=53f1 df80469c5c91b51bfdac1e03f85e

Da Cunha Pereira, Rodrigo, Diccionario de Direito de familia e Sucessões: Ilustrado, São Paolo, Saraiva, 2015, p. 337.

FAmÁ, MARÍA Victoria, La filiación. Régimen constitucional, civil y procesal, Buenos Aires, Abeledo Perrot, 2009, p. 52.

Ferreira de Lira, Daniel y Braga de Soares Carvalho, Dimitre, "O material humano criopreservado e a filiação tecnológica: um debate em torno da filiação no Direito de Família”, Jus Navigandi, agosto, 2012, vol. 17. [Consulta: 9 de agosto, 2012]. Disponible en http://jus.com.br/revista/texto/22347

Garcia de Solavagione, Alicia, "Filiación por naturaleza o biológica”, en Guillermo Borda (dir.), Derecho de familia y de las personas: entre el Derecho dado y el Derecho proyectado, Córdoba, Nuevo Enfoque Jurídico, 2014, p.123.

Kemelmajer de Carlucci, Aída; Herrera, Marisa y Lamm, Eleonora, "Filiación derivada de la reproducción asistida. Derecho a conocer los orígenes, a la información y al vínculo jurídico”, La Ley, octubre, 2012, No. 189.

Kemelmajer de Carlucci, Aída; Herrera, Marisa y Lloveras, Nora, Tratado de Derecho de Familia (Según el Código Civil y Comercial de 2014), tomo 2, Santa Fe, Rubinzal-Culzoni, 2014.

Krasnow, Adriana N. Pruebas biológicas y filiación, Rosario, unR, 1996, p. 49 y ss.

Krasnow Adriana N. Filiación: Determinación de la maternidad y paternidad, Buenos Aires, La Ley.

Krasnow, Adriana N. “La filiación y sus fuentes”, La Ley, 2005-A, p. 1458.

LôBo, Paulo. Dirieto Civil. Familias, São Paolo, Saraiva, p. 199.

Madaleno, Rolf, Curso de direito de família, Rio de Janeiro, Forense, 2015, p. 571.

Medina, Graciela y Roveda, Eduardo Guillermo, Manual de Derecho de familia, Buenos Aires, Abeledo Perrot, 2016, p. 514.

Miranda LunA, RaÚl E., Bioética y Derecho de familia: problemas actuales sobre filiación y responsabilidad, Bogotá, Universidad del Externado de Colombia, 2002, p. 300.

Morán De Vicenzi Claudia, El concepto de filiación en la fecundación artificial, Lima, ARA, Lima, 2005.

Mosquera VÁsquez, Clara Celinda, “El primer caso de vientre de alquiler”, Diálogos con la Jurisprudencia, agosto, 2012, vol. 18, No. 167, p. 55 y ss.

Pereira, Caio Mário Da Silva, Instituições de Direito Civil, tomo 5, Río de Janeiro, Forense, 2004, p. 312. 
Sambrizzi, Eduardo A., La filiación en el Código Civil y Comercial la procreación asistida, Buenos Aires, La Ley, 2016, p. 68.

Seleme, Hugo Omar, "La maternidad por subrogación y los límites de la autonomía" La Ley, enero, 2013, vol. 77, No. 13, p. 2.

Sesta, Michele, "Filiazione”, en Enciclopedia del Diritto, Aggiornamento, tomo 4, Milán, Giuffré, 2002.

Werner, Matías, “La voluntad procreación al hace a la madre”, Diario Judicial, No. 4223, [Consulta: 21 de marzo, 2016], Disponible en http://www.diariojudicial.com/nota/74754 
